\title{
A Comparative Study of the Fragmentation of Neutral Lactooligosaccharides in Negative- Ion Mode by UV-MALDI-TOF and UV- MALDI Ion-Trap/TOF Mass Spectrometry
}

\author{
Tohru Yamagaki, Hiroaki Suzuki, and Kazuo Tachibana \\ Department of Chemistry, School of Science, The University of Tokyo, Tokyo, Japan
}

\begin{abstract}
Structure analyses of underivatized neutral lacto oligosaccharides are systematically performed by ultraviolet matrix-assisted laser desorption/ionization time-of-flight mass spectrometry (UVMALDI TOF MS) and UV-MALDI ion-trap time-of-flight mass spectrometry (ion-trap/TOF MS) acquired in negative-ion mode. Interestingly, their fragmentation significantly differ each other. In postsource decay (PSD) in UV-MALDI TOF MS, cross-ring cleavage at the reducing terminal predominates. On the other hand, glycosyl bond cleavage (C-type fragmentation) takes place preferentially in collision induced dissociation (CID) in UV-MALDI ion-trap/TOF MS. The cross-ring cleavage in PSD similar to that in in-source decay occurs via a prompt reaction path characteristic of the UV-MALDI process itself. The product ion spectra of UV-MALDI ion-trap/ TOF MS are similar to the electrospray ionization (ESI) ion-trap or quadrupole/TOF CID product ion spectra. During ion-trap/TOF MS experiments, the deprotonated molecular ions survive for several tens of milliseconds after CID event because the high internal energy chlorinated precursor ions are cooled by collisional cooling in the ion trap. The results obtained suggest that the PSD from the chlorinated precursor ion in UV-MALDI TOF MS might proceed as a two-step reaction; in the first, a high internal energy deprotonated molecular ion is generated as a reaction intermediate during the flight in the drift tube, and in the second, the rapid decomposition from the deprotonated molecular ion takes place. (J Am Soc Mass Spectrom 2006, 17, 67-74) (C) 2005 American Society for Mass Spectrometry
\end{abstract}

$O^{\mathrm{t}}$ tructural analyses of carbohydrates and oligosaccharides are performed by mass spectrometry [1]. With the appropriate ionization methods and type of MS instrument, fragment ions, whose various kinds of decomposition are known, can provide structural information in product ion spectra [2]. In UV matrix-assisted laser desorption/ionization mass spectrometry (UV-MALDI MS) of neutral oligosaccharides, positively charged ions are detected as cation adduct ions rather than as protonated ions. Under common measurement conditions, employing a matrix of 2,5-dihydroxybenzoic acid (DHBA), a sodiated molecular ion $\left[\mathrm{M}+\mathrm{Na}^{+}\right.$is preferentially observed in positive-ion UV-MALDI mass spectra of neutral oligosaccharides [3].

Conventionally, UV-MALDI is combined with time-offlight mass spectrometry (TOF-MS); a structural analysis can be performed using postsource decay (PSD) ions produced by spontaneous decay during the time of flight of metastable ions generated by laser irradiation [4]. In the PSD of oligosaccharides, glycosyl bond cleavage ions (Yand B-type fragment; Domon and Costello nomenclature [5]) are generally observed from a sodiated precursor ion $[\mathrm{M}+\mathrm{Na}]^{+}$in the positive-ion UV-MALDI PSD spectra

Published online December 15, 2005

Address reprint requests to Dr. T. Yamagaki, Department of Chemistry, School of Science, The University of Tokyo, 7-3-1 Hongo, Bunkyo-ku, Tokyo 113-0033, Japan. E-mail: yamagaki@chem.s.u-tokyo.ac.jp
[6]. Cross-ring cleavage ions are observed, however, and their relative abundance tends to be low $[7,8]$. In our previous study, these ions were generated from $\beta 1-4$ linked $N$-acetyl glucosamine residue (GlcNAc) at the reducing terminal in Lewis ${ }^{\mathrm{X}}$ trisaccharide, but they were not generated from the terminal glucose (Glc) in 3-fucosyl lactose [9]. Positive-ion UV-MALDI TOF MS measurements yield information about molecular weights and sugar sequences. In electrospray ionization MS analysis of positively charged ion detection, Y- and B-type fragment ions are predominant in the low-energy collisioninduced dissociation (CID) MS/MS spectra [10], which is very similar to the UV-MALDI PSD spectra of neutral oligosaccharides.

Recently, structure analyses of neutral lactooligosaccharides, including many branching and linkage isomers, were performed by negative-ion ESI-MS techniques using low-energy CID-MS/MS spectra acquired by quadrupole time-of-flight (Q-TOF) MS and ion-trap MS instruments, which showed the sequential C-type ions produced by glycosyl bond cleavage and linkage dependent product ions $[11,12]$. On the other hand, we studied the decomposition of ions originating from neutral oligosaccharides by means of UV-MALDI MS in negatively charged ion detection [13]. Negative-ion mode measurements of neutral oligosaccharides in UV-MALDI TOF MS have been rarely achieved [14-17]. Until now, it was difficult to detect deprotonated molecular ions of neutral oligosac- 
charides without $\beta$-carbolines as a matrix $[16,17]$. In the linear-mode of UV-MALDI TOF MS in negatively charged ion measurements, we invariably detected the cross-ring cleavage ions in large abundance [13]. These cross-ring cleavage ions were very informative for analysis of the glycosyl bond type. We could acquire the PSD spectra from a stable, chlorinated precursor ion $\left[\mathrm{M}+\mathrm{Cl}^{-}\right.$, and the PSD spectra of the linear oligosaccharides showed a spectra similar to the ISD ones; the cross-ring cleavage ions predominated, rather than the glycosyl bond cleavage fragment ions. These trends in the UV-MALDI PSD spectra differ greatly from those in the ESI low-energy CID product ion spectra in the negative-ion MS measurements.

Here, we focus our attention on these differences between UV-MALDI PSD and ESI CID product ion spectra in negatively charged ion detection, in an attempt to study the characteristics of the UV-MALDI PSD of neutral oligosaccharides. We also compare them with UV-MALDI CID product ion spectra acquired by ion-trap time-offlight (ion-trap/TOF) mass spectrometry [18]. In addition, we demonstrate the usefulness of UV-MALDI PSD measurements in negatively charged ion detection for the structural analysis of branching and linkage isomeric lactooligosaccharides.

\section{Experiments}

\section{Samples}

Scheme of analyte sugar structures are listed in Table 1. All analytes were purchased from Sigma (St. Louis, $\mathrm{MO}$ ). Analytes were dissolved in Milli-Q (Millipore Co., Billerica, MA) water at a final concentration of 1.5 $\mathrm{mg} / \mathrm{mL}$.

7-methoxy-1-methyl-9H-pyrido[3,4-b]indole (harmine) was used as a matrix and dissolved in methanol at the concentration of $10 \mathrm{mg} / \mathrm{mL}$. One hundred $\mathrm{mM}$ ammonium chloride aqueous solution was used as an additive. Mixed crystal of sample and matrix on target was prepared by sandwich method described in [19]; $0.5 \mu \mathrm{L}$ aliquot of matrix solution is deposited on the target plate and dried to matrix layer. Then, $0.5 \mu \mathrm{L}$ aliquots of sample solution and $\mathrm{NH}_{4} \mathrm{Cl}$ additive were deposited successively. After another aliquot of matrix solution was deposited, the target plate was dried up completely.

\section{Mass Spectrometry}

The PSD spectra of UV-MALDI TOF MS were acquired with an AXIMA-CFR instrument (Shimadzu-Kratos Corp., Kyoto, Japan) equipped with a pulsed $\mathrm{N}_{2}$ laser (337 $\mathrm{nm})$. Each spectrum was measured at an acceleration energy of $20 \mathrm{kV}$ using pulsed delayed extraction for canceling dispersive initial velocity and broad kinetic energy of the ions. Each spectrum represents an average of 100 laser shots.

All UV-MALDI CID product ion spectra were acquired by a ion-trap/TOF MS of AXIMA QIT-TOF
Table 1. Structure of oligosaccharides

\begin{tabular}{|c|c|}
\hline Oligosaccharides & Sequences \\
\hline $\begin{array}{l}\text { Lacto- } N \text {-tetraose } \\
\text { LNT }\end{array}$ & Gal $\beta 1-3 \mathrm{GIcNAc} \beta 1-3 \mathrm{Gal} \beta 1-4 \mathrm{Glc}$ \\
\hline $\begin{array}{l}\text { Lacto- } N \text {-neotetraose } \\
\qquad \text { LNnT }\end{array}$ & Gal $\beta 1-4 \mathrm{GlcNAc} \beta 1-3 \mathrm{Gal} \beta 1-4 \mathrm{Glc}$ \\
\hline $\begin{array}{l}\text { Lacto- } N \text {-fucopentaose I } \\
\text { LNFP-I }\end{array}$ & $\begin{array}{l}\text { Gal } \beta 1-3 \mathrm{GlcNAc} \beta 1-3 \mathrm{Gal} \beta 1-4 \mathrm{Glc} \\
2 \\
\mid \\
\text { Fuc } \alpha 1\end{array}$ \\
\hline $\begin{array}{l}\text { Lacto- } N \text {-fucopentaose II } \\
\text { LNFP-II }\end{array}$ & $\begin{array}{c}\text { Fuc } \alpha 1-4 \mathrm{GlcN} A c \beta 1-3 \mathrm{Gal} \beta 1-4 \mathrm{Glc} \\
3 \\
\mid \\
\text { Gal } \beta 1\end{array}$ \\
\hline $\begin{array}{l}\text { Lacto- } N \text {-fucopentaose III } \\
\text { LNFP-III }\end{array}$ & $\begin{array}{l}\text { Gal } \beta 1-4 \mathrm{GlcNAc} \beta 1-3 \mathrm{Gal} \beta 1-4 \mathrm{Glc} \\
3 \\
\text { Fuc } \alpha 1\end{array}$ \\
\hline $\begin{array}{l}\text { Lacto- } N \text {-difucohexaose I } \\
\text { LNDFH-I }\end{array}$ & $\begin{array}{cc}\text { Gal } \beta 1-3 & \text { GlcNAc } \beta 1-3 G a l \beta 1-4 G l c \\
2 & 4 \\
\text { Fuc } \alpha 1 & \text { Fuc } \alpha 1\end{array}$ \\
\hline $\begin{array}{l}\text { Lacto- } N \text {-difucohexaose II } \\
\text { LNDFH-II }\end{array}$ & $\begin{array}{rr}\text { Fuc } \alpha 1-4 \mathrm{GlcN} A c \beta 1-3 \mathrm{Gal} \beta 1-4 \mathrm{Glc} \\
3 & 3 \\
\text { Gal } \beta 1 & \text { Fuc } \alpha 1\end{array}$ \\
\hline
\end{tabular}

instrument (Shimadzu-Kratos Corp.) equipped with a pulsed $\mathrm{N}_{2}$ laser (337 nm). Helium gas was injected in the ion-trap cell at the laser irradiation and the ion trapping for collisional cooling according to the instrument system's procedure. Argon gas was injected at the collision-induced dissociation of the ions and the exciting voltage was charged.

\section{Results and Discussion}

The PSD spectra and product ion spectra of neutral oligosaccharides were measured by negative-ion mode from the chlorinated molecular ion $[\mathrm{M}+\mathrm{Cl}]^{-}$using UV-MALDI TOF and ion-trap/TOF MS. All PSD and product ions were detected as deprotonated ions.

\section{PSD Spectra of UV-MALDI TOF MS}

LNT and LNnT. Figure 1 shows the PSD spectra of lacto $\mathrm{N}$-tetraose (LNT), and lacto $\mathrm{N}$-neotetraose (LNnT) obtained from the chlorinated molecular ion $[\mathrm{M}+\mathrm{Cl}]^{-}$at $m / z$ 742. The deprotonated molecule $\left[\mathrm{M}-\mathrm{H}^{-}\right.$is not observed. However, the fact that all the PSD ions were detected as the deprotonated form suggests that these deprotonated molecules are very unstable in PSD. The PSD ion signals for $\left[\mathrm{M}-\left(\mathrm{C}_{2} \mathrm{H}_{4} \mathrm{O}_{2}\right)-\mathrm{H}_{2} \mathrm{O}-\mathrm{H}\right]^{-}$at $m / z$ 628 , and $\left[\mathrm{M}-\left(\mathrm{C}_{4} \mathrm{H}_{8} \mathrm{O}_{4}\right)-\mathrm{H}\right]^{-}$at $m / z 586$ are produced by cross-ring cleavage at the reducing terminal; they are assigned to the ${ }^{0,2} \mathrm{~A}-\mathrm{H}_{2} \mathrm{O}$ and ${ }^{2,4} \mathrm{~A}$-type ions, respectively. The high abundance of the ions ${ }^{0,2} \mathrm{~A}-\mathrm{H}_{2} \mathrm{O}$ and ${ }^{2,4} \mathrm{~A}$ among the cross-ring cleavage ions at the reducing terminal and the observation of the B-type ion at $m / z 526$ suggest that the reducing terminal glucose binds by 1-4 glycosyl bond. The cross-ring cleavage ions were also 

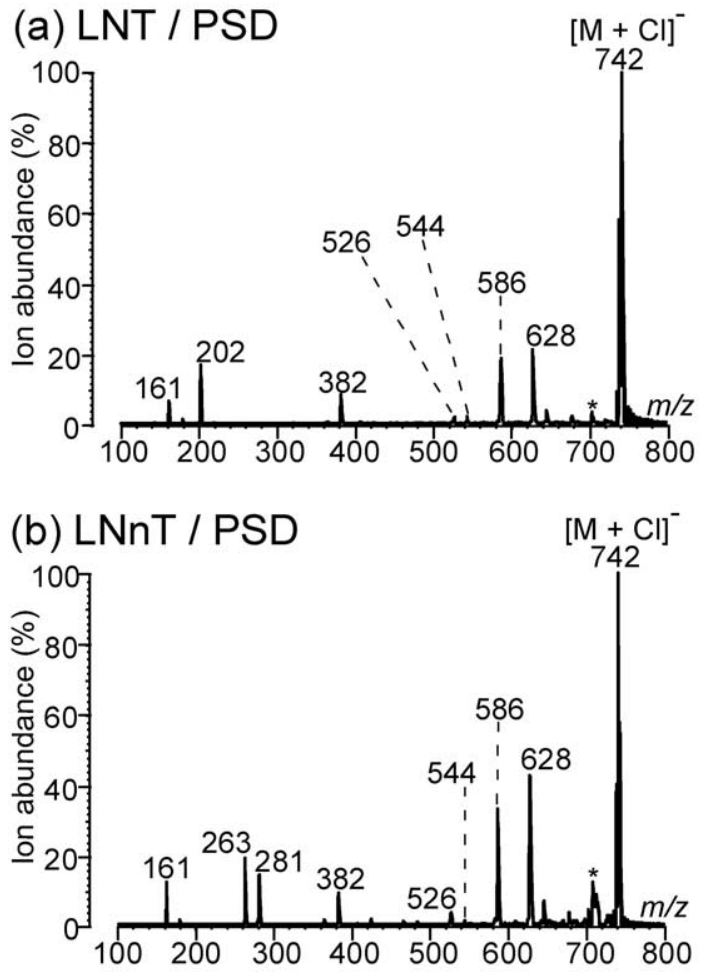

Figure 1. PSD spectra of LNT (a) and LNnT (b) from the chlorinated molecular ion $[\mathrm{M}+\mathrm{Cl}]^{-}$by negative-ion UV-MALDI TOF MS. The broad ion signal labeled by an asterisk is observed at $\mathrm{m} / \mathrm{z} 714$, a location which differs from that of the deprotonated molecule $(\mathrm{m} / \mathrm{z} 706)$.

detected from the 4-linked Glc at the reducing terminal in the negative-ion fast-atom bombardment mass spectra (FAB-MS), [20] and in the in-source decay spectra of negative-ion UV-MALDI TOF MS [13]. We discussed the relative abundance of the cross-ring cleavage ions as a means of identifying the glycosyl bond types in our previous paper [13]. The PSD spectral patterns of LNT and $\mathrm{LNnT}$ in the cross-ring cleavage ions at the reducing terminal are consistent with those of $\beta 1-4$ linked oligosaccharides.

The PSD ion signals at $m / z 544\left(\mathrm{C}_{3}\right), m / z 382\left(\mathrm{C}_{2}\right)$, and $\mathrm{m} / \mathrm{z} 179\left(\mathrm{C}_{1}\right)$ are C-type fragment ions produced by glycosyl bond cleavage. In the PSD spectra, these C-type ions are much less abundant than the A-type fragment ions and do not play a major role. Since the PSD ions at $m / z 382$ are produced by the glycosyl bond cleavage at the amino sugar residue of GlcNAc, the ions of that $\mathrm{m} / \mathrm{z}$ value are exceptionally abundant [21,22]. The double cleavage ions at $m / z 202$ are also plentiful because of the amino sugar cleavage and the $\beta$-elimination at the $\mathrm{C}-3$ position of GlcNAc. Since the acetoamido group binds to the $\mathrm{C}-2$ position of GlcNAc, which adjoins the anomeric $(\mathrm{C}-1)$ and $\mathrm{C}-3$, it promotes this the fragmentation at the $\mathrm{C}-1$ and $\mathrm{C}-3$ positions of GlcNAc.

The compounds LNT and LNnT are linkage isomers; the non-reducing terminal Gal binds to GlcNAc via the $\beta 1-3$ linkage in LNT, and the $\beta 1-4$ linkage in LNnT. These isomeric lactotetraoses are distinguished by their PSD spectra. The PSD ions at $m / z 202$ are detected only in the spectrum of LNT, not in the spectrum of LNnT (Figure 1); the PSD ions are generated by a double cleavage of the glycosyl bonds $\left(C_{2} / Z_{3}\right)$. The $\beta$-elimination occurs at the C-3 position of GlcNAc specifically at 1-3 linkages (Z-type fragmentation), and the glycosyl bond between GlcNAc and Gal cleaves at the GlcNAc side (C-type fragmentation). The PSD spectrum of $\mathrm{LNnT}$ shows a ${ }^{0,2} \mathrm{~A}$ cross-ring cleavage at the 4-linked GlcNAc and a subsequent dehydration; that is, PSD ion signals $\left[\mathrm{M}-\mathrm{anGlc}_{2}-{ }^{0,2} \mathrm{~A}_{2}-\right.$ $\mathrm{H}]^{-}$at $m / z 281$ and $\left[\mathrm{M}-\operatorname{anGlc}_{2}-{ }^{0,2} \mathrm{~A}_{2}-\mathrm{H}_{2} \mathrm{O}\right]^{-}$at $m / z$ 263 are observed. These ions are characteristic of the presence of a $\beta 1-4$ linked GlcNAc residue in which the C-3 position is not occupied. Such linkage-dependent fragmentations also appear in the negative-ion ESI-CID product ion spectra of LNT and LNnT [11, 12], where they enable us to identify the structure of lactooligosaccharides.

\section{PSD Spectra of Lactooligosaccharides}

The PSD of lactooligosaccharides depends on their structures, and common PSD fragments are generated by the
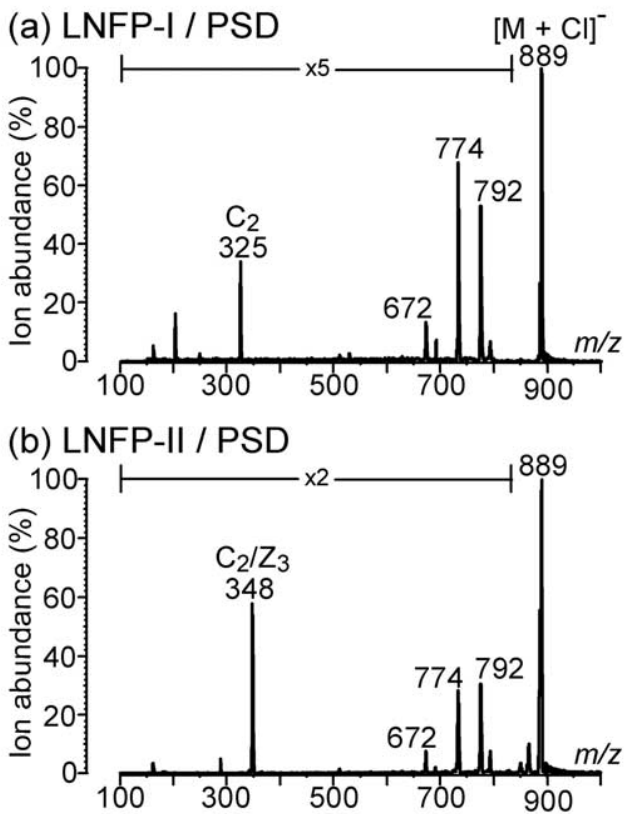

(c) LNFP-III / PSD

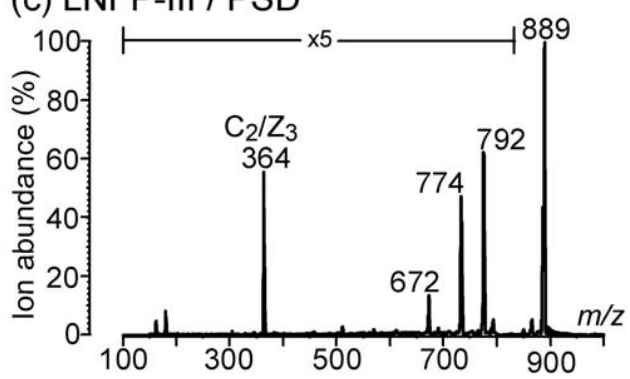

Figure 2. PSD spectra of LNFP-I (a), LNFP-II (b), and LNFP-III (c) from the chlorinated molecular ion $[\mathrm{M}+\mathrm{Cl}]^{-}$by negative-ion UV-MALDI TOF MS. 
Table 2. Assignments and relative abundance of PSD ions of UV-MALDI TOF MS and CID product ions of ion-trap/TOF MS

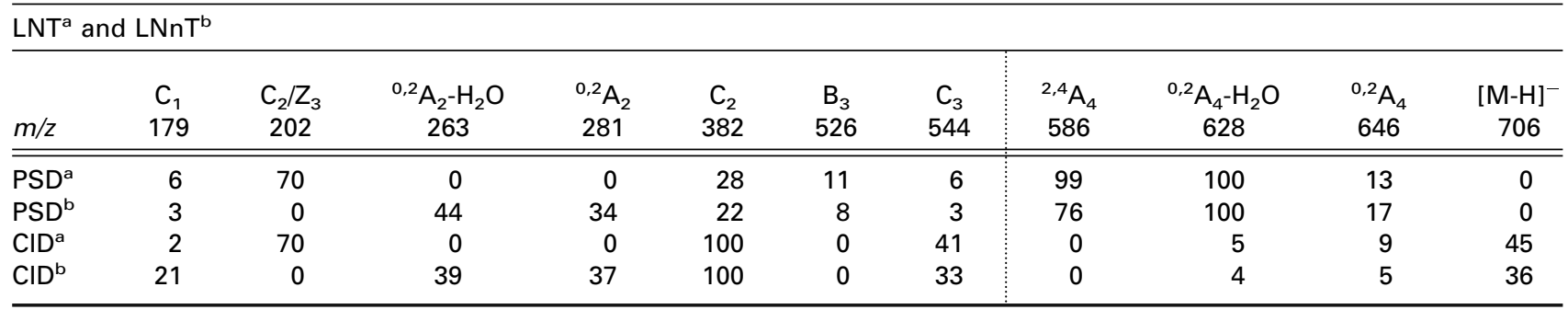

LNFP I ${ }^{\mathrm{c}} \&$ LNFP $\|^{\mathrm{d}} \&$ LNFP III

\begin{tabular}{|c|c|c|c|c|c|c|c|c|c|c|c|c|}
\hline$m / z$ & $\begin{array}{c}C_{1} \\
179\end{array}$ & $\begin{array}{c}\mathrm{C}_{3} / \mathrm{Z}_{3}{ }^{\mathrm{C}} \\
202\end{array}$ & $\begin{array}{l}\mathrm{C}_{2}{ }^{\mathrm{c}} \\
325\end{array}$ & $\begin{array}{c}\mathrm{C}_{2} / \mathrm{Z}_{3}{ }^{\mathrm{d}} \\
348\end{array}$ & $\begin{array}{c}\mathrm{C}_{2} / \mathrm{Z}_{3}{ }^{\mathrm{e}} \\
364\end{array}$ & $\begin{array}{c}\mathrm{C}_{2 \text { or } 3^{\mathrm{f}}} \\
528\end{array}$ & $\begin{array}{c}\mathrm{B}_{3 \text { or } 4^{\mathrm{g}}} \\
672\end{array}$ & $\begin{array}{c}C_{3 \text { or } 4^{g}} \\
690\end{array}$ & $\begin{array}{l}{ }^{2,4} \mathrm{~A}^{\mathrm{h}} \\
732\end{array}$ & $\begin{array}{c}{ }^{0,2} \mathrm{~A}-\mathrm{H}_{2} \mathrm{O}^{\mathrm{h}} \\
774\end{array}$ & $\begin{array}{c}{ }^{0,2} A^{h} \\
792\end{array}$ & $\begin{array}{c}{[\mathrm{M}-\mathrm{H}]^{-}} \\
852\end{array}$ \\
\hline $\mathrm{PSD}^{\mathrm{c}}$ & 0 & 21 & 44 & 0 & 0 & 0 & 20 & 10 & 100 & 74 & 8 & 0 \\
\hline $\mathrm{PSD}^{\mathrm{d}}$ & 0 & 0 & 0 & 100 & 0 & 0 & 12 & 0 & 52 & 60 & 17 & 0 \\
\hline $\mathrm{PSD}^{\mathrm{e}}$ & 10 & 0 & 0 & 0 & 74 & 0 & 19 & 0 & 72 & 100 & 8 & 0 \\
\hline $\mathrm{CID}^{\mathrm{c}}$ & 0 & 0 & 100 & 0 & 0 & 16 & 0 & 44 & 0 & 3 & 6 & 6 \\
\hline $\mathrm{CID}^{\mathrm{d}}$ & 0 & 0 & 0 & 100 & 0 & 19 & 0 & 40 & 0 & 1 & 2 & 17 \\
\hline $\mathrm{CID}^{\mathrm{e}}$ & 0 & 0 & 0 & 0 & 100 & 7 & 0 & 28 & 0 & 5 & 2 & 15 \\
\hline
\end{tabular}

LNDFH I' \& LNDFH IIj

\begin{tabular}{|c|c|c|c|c|c|c|c|c|c|c|c|c|}
\hline$m / z$ & $\begin{array}{c}\mathrm{C}_{2}{ }^{\mathrm{i}} \\
325\end{array}$ & $\begin{array}{c}\mathrm{C}_{2} / \mathrm{Z}_{3} \\
348\end{array}$ & $\begin{array}{c}C_{2}{ }^{j} \\
528\end{array}$ & $\begin{array}{c}B_{3} \\
656\end{array}$ & $\begin{array}{l}\mathrm{C}_{3}{ }^{\mathrm{i}} \\
674\end{array}$ & $\begin{array}{l}\mathrm{C}_{3}{ }^{\mathrm{i}} \\
690\end{array}$ & $\begin{array}{c}\mathrm{B}_{4} \\
818\end{array}$ & $\begin{array}{c}C_{4} \\
836\end{array}$ & $\begin{array}{c}{ }^{2,4} A_{5} \\
878\end{array}$ & $\begin{array}{c}{ }^{0,2} \mathrm{~A}_{5}-\mathrm{H}_{2} \mathrm{O} \\
920\end{array}$ & $\begin{array}{c}{ }^{0,2} A_{5} \\
938\end{array}$ & $\begin{array}{c}{[\mathrm{M}-\mathrm{H}]^{-}} \\
998\end{array}$ \\
\hline PSD $^{f}$ & 12 & 61 & 0 & 5 & 0 & 0 & 37 & 0 & 100 & 41 & 7 & 0 \\
\hline $\mathrm{PSD}^{\mathrm{g}}$ & 0 & 100 & 0 & 0 & 0 & 10 & 0 & 0 & 0 & 0 & 0 & 0 \\
\hline $\mathrm{CID}^{\mathrm{f}}$ & 27 & 100 & 0 & 0 & 44 & 0 & 0 & 58 & 0 & 5 & 3 & 13 \\
\hline $\mathrm{CID}^{\mathrm{g}}$ & 0 & 100 & 26 & 0 & 0 & 90 & 0 & 0 & 0 & 0 & 0 & 1 \\
\hline
\end{tabular}

${ }^{a}$ data of LNT.

${ }^{b}$ data of LNnT.

${ }^{c}$ data of LNFP-I.

data of LNFP-II.

edata of LNFP-III.

fassignment of LNFP-I is $\mathrm{C}_{3}$, those of LNFP-II \& -III are $\mathrm{C}_{4}$.

${ }^{g}$ assignments of LNFP-I are $B_{4}$ and $C_{4}$, those of LNFP-II \& -III are $B_{3}$ and $C_{3}$.

hassignment of LNFP-I is $A_{5}$, and those of LNFP-II \& -III are $A_{4}$.

idata of LNDFH-I.

jdata of LNDFH-II.

${ }^{k}$ Relative ion abundances are normerized to the most abundant ion amoung the PSD and product ions.

analytes with the same structural units. The Z-type fragmentation at 3-linked GlcNAc occurs in the PSD of all analytes. Here, the double cleavage of the C-and Z-types (C/Z-type fragmentation) is also useful to elucidate the structures. Therefore, a systematic structural analysis of the lactooligosaccharides can be performed by this technique. For example, as shown in Figure 2, three isomers of the mono-fucosyl lactopentaoses of LNFP-I, -II, and -III can be identified from their C-type ion and double cleavage ions $C_{2} / Z_{3}$ because the fucose binding site in each of the isomers is different (see the structures in Table 1). Since the fucosyl bond rarely cleaves in negative-ion mode experiments without a Z-type fragmentation at the 3-linked GlcNAc, LNFP-I and LNFP-II can be distinguished.

The cross-ring cleavage of the 4-linked glucose takes place at the reducing terminal of lactooligosaccharides, and, as indicated in Figures 1 and 2, their PSD ions predominate in the spectra. All the spectral data are summarized in Table 2. The relative ion abundances are shown as percentage (\%) normalized to the highest ion signal among PSD or product ions. The relative abundance of the cross-ring cleavage ions is presented on the right side of the dotted lines in Table 2. Their total amount is much higher than those of the other ions on the left side in Table 2, as is apparent from the data row of an analyte in the PSD spectra results. This abundance is characteristic of the PSD ions. Surprisingly, no cross-ring cleavage ions are observed from the PSD spectrum of LNDFH-II (Figure 3); as shown in Table 1, not only the C-4 but also the C-3 positions in the reducing terminal glucose are occupied by galactose and fucose residues in the structure of LNDFHII. From that result, we can easily distinguish between LNDFH-I and -II.

The C-type fragment ions are also observed, but their abundances are so low that C-type fragmentation must progress poorly, except for the C-type ions originating from the cleavage of the amino sugar glycosyl bond as described in the lactotetraoses. The PSD spectra might be less informative for the C-type fragmentation for just 
(a) LNDFH-I / PSD

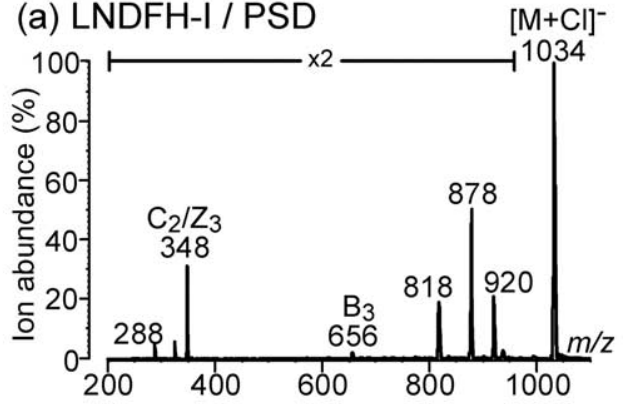

(b) LNDFH-II / PSD

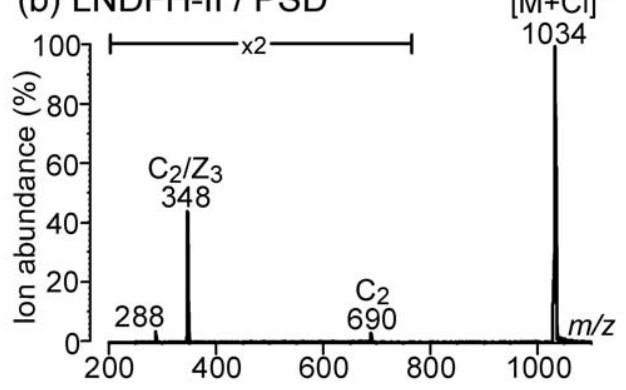

Figure 3. PSD spectra of LNDFH I (a) and LNDFH II (b) from the chlorinated molecular ion $[\mathrm{M}+\mathrm{Cl}]^{-}$by negative-ion UV-MALDI TOF MS.

the sequence of the sugar residues; however, the positive-ion mode PSD spectra, which showed the sequential fragment ions produced by the glycosyl bond cleavage (Y-, B-, and C-type fragmentation) [6], can compensate for the ambiguous and insufficient sequential information in the negative-ion PSD analysis. Harmine works as an effective matrix both in the positive- and the negative-ion mode UV-MALDI MS of neutral oligosaccharides [16]. Therefore, the PSD analyses of oligosaccharides by both positive- and negative-ion mode measurements provide sufficient information for a systematic structural analysis.

\section{CID Product Ion Spectra of Ion-Trap/TOF MS}

LNT and LNnT. Figure 4 shows the product ion spectra of LNT and LNnT from the chlorinated precursor ion $[\mathrm{M}+\mathrm{Cl}]^{-}$at $m / z 742$ taken by UV-MALDI ion-trap/TOF MS. The deprotonated ion $[\mathrm{M}-\mathrm{H}]^{-}$at $\mathrm{m} / \mathrm{z} 706$ is clearly observable, thus differing from the PSD spectra (Figure 1). The C-type fragment ions at $\mathrm{m} / \mathrm{z} 544\left(\mathrm{C}_{3}\right)$ and $\mathrm{m} / \mathrm{z} 382\left(\mathrm{C}_{2}\right)$ are present in high abundance and their relative ion abundances are much higher than those of the cross-ring cleavage ions from the reducing terminal (Figure 4). In addition, we observed the cross-ring cleavage ion ${ }^{0,2} \mathrm{~A}_{4}$ at $m / z 646$ and the ion $\left({ }^{0,2} \mathrm{~A}_{2}-\mathrm{H}_{2} \mathrm{O}\right)$ at $m / z 628$, rather than the ion ${ }^{2,4} \mathrm{~A}_{4}$ at $m / z 586$, which dominated in the PSD spectra. These results differ significantly from those seen in the PSD spectra.

The linkage-dependent fragment ions commonly appear both in the PSD and CID product ion spectra. The double cleavage product ion from 3-linked GlcNAc at $\mathrm{m} / \mathrm{z}$ $202\left(C_{2} / Z_{3}\right)$ is found in the spectra of LNT, and the ${ }^{0,2} \mathrm{~A}$-type cross-ring cleavage ion at $\mathrm{m} / \mathrm{z} 281$ and the dehydrated ion of the ${ }^{0,2} \mathrm{~A}$ ion from 4-linked GlcNAc at $\mathrm{m} / \mathrm{z} 263$ are noted in the spectra of LNnT. Thus, the UV-MALDI CID-MS/MS spectra produced by ion-trap/ TOF MS are useful for the structure identification of the isomeric oligosaccharides.

\section{CID Product Ion Spectra of Lactooligosaccharides}

A systematic identification of the structure of lactooligosaccharides was also carried out through a CID product ion analysis of ion-trap/TOF MS. The spectral patterns of the product ion spectra are similar to those of the ESI CID product ion spectra generated by Q-TOF and ion-trap mass spectrometry [11, 12]. There are two points of interest with regard to the characteristics of the product ion spectra taken by ion-trap/TOF MS. The first is that the sequential C-type ions predominate. The second is that the cross-ring cleavage ions from the reducing terminal are sparse, as described for LNT and LNnT (Figures 1 and 4). Figure 5 shows the difference between the PSD and CID product ion spectra of LNT and LNnT. The red dotted lines show the predominant PSD ions; the blue dotted lines indicate the most common CID product ions in their spectra. The total amounts of the cross-ring cleavage ion abundances on the right side of the dotted lines of the CID product ion data in Table 2 are much lower than those of
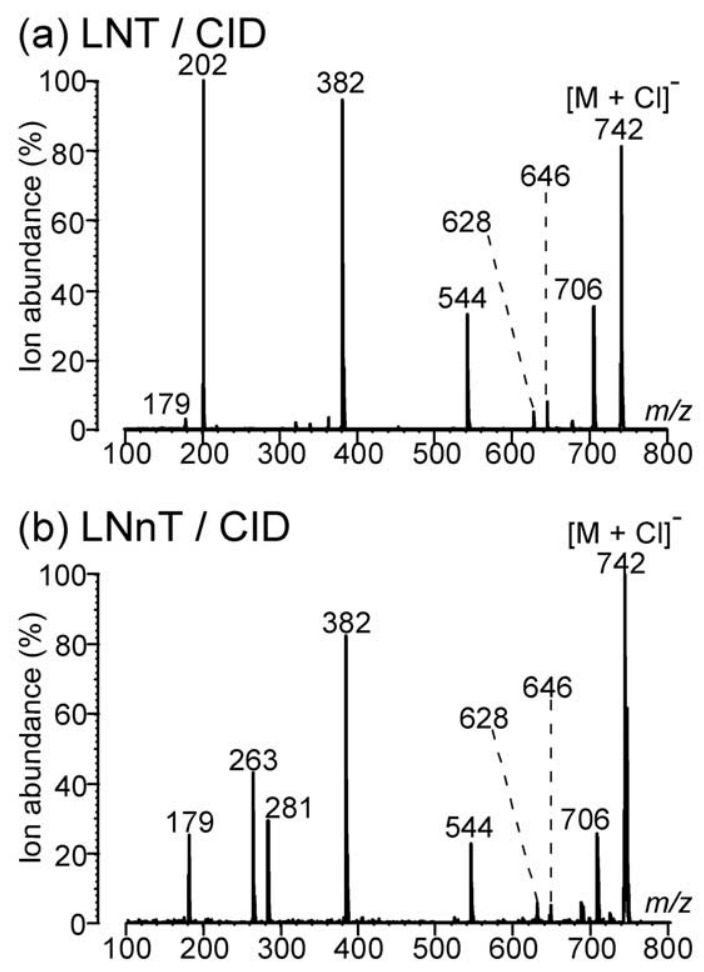

Figure 4. CID product ion spectra of LNT (a) and LNnT (b) from the chlorinated molecular ion $[\mathrm{M}+\mathrm{Cl}]^{-}$by negative-ion $\mathrm{UV}$ MALDI ion-trap/TOF MS. 


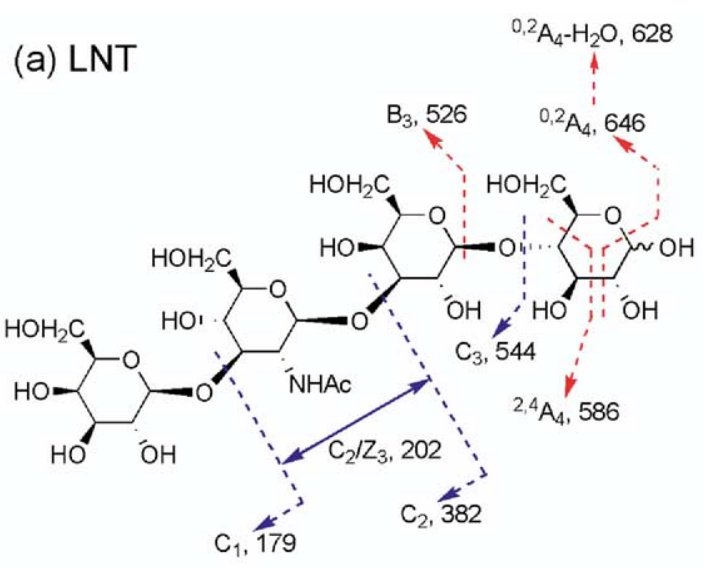

(b) LNnT

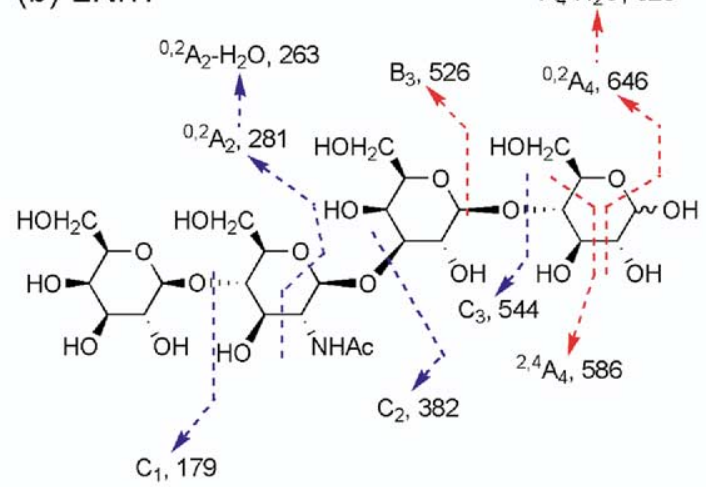

Figure 5. Fragmentation scheme of LNT (a) and LNnT (b). The red lines indicate the predominant ions in the PSD spectra and the blue lines the predominant ions in the CID product ion spectra.

the left side product ions, as seen in the row of data for an analyte in Table 2. In addition, the deprotonated molecule $[\mathrm{M}-\mathrm{H}]^{-}$is clearly observed in the CID product ion spectra of all analytes, a finding that differs from the PSD spectra results. These two points, pertaining to the characteristics of the CID product ion spectra and to the observation of deprotonated molecules, mark the differences between the CID product ion spectra and the PSD spectra.

To study the difference between the CID product ion spectra and the PSD spectra, we considered that the relative abundances of the three cross-ring cleavage ions from the reducing terminal ${ }^{0,2} \mathrm{~A},{ }^{0,2} \mathrm{~A}-\mathrm{H}_{2} \mathrm{O},{ }^{2,4} \mathrm{~A}$ could show a characteristic fragmentation. The ${ }^{0,2} \mathrm{~A}$ ion is most plentiful in the product ion spectra of ion-trap/TOF MS; on the other hand, in PSD spectra, ${ }^{0,2} \mathrm{~A}-\mathrm{H}_{2} \mathrm{O}$ or ${ }^{2,4} \mathrm{~A}$ ions are more common than ${ }^{0,2} \mathrm{~A}$ ion at the reducing terminal (Table 2). The ${ }^{0,2} \mathrm{~A}-\mathrm{H}_{2} \mathrm{O}$ and ${ }^{2,4} \mathrm{~A}$ ions are thought to be formed via ${ }^{0,2} \mathrm{~A}$ ions in the proposed fragmentation mechanism [20,23]. Thus, we expected that the PSD ions would be more decomposed than the CID product ions from ion-trap/TOF MS.

On the other hand, there are common fragmentations found in both the PSD and CID product ion spectra of ion-trap/TOF MS. The ${ }^{0,2} \mathrm{~A}$ cross-ring cleavage ion species originates in a 4-linked GlcNAc whose C-3 position is not occupied, for instance, the ions ${ }^{0,2} \mathrm{~A}_{2}$, and ${ }^{0,2} \mathrm{~A}_{2}-\mathrm{H}_{2} \mathrm{O}$ appear in the spectrum of LNnT. A double cleavage of the glycosyl bonds around the GlcNAc, of both the C- and Z-type fragmentations $(\mathrm{C} / \mathrm{Z})$, occurred at the 3-linked GlcNAc; as an example, the ion $C_{2} / Z_{3}$ is present in the spectrum of LNT. These structurally dependent fragmentations in the CID of ion-trap/TOF MS also enable us to identify the structure of the lactooligosaccharides.

\section{Collisional Cooling of Excited Analyte Molecular Ions in UV-MALDI}

In laser desorption, solid-phase molecules irradiated by laser are rapidly heated and sublimed. Simultaneously, the molecules are highly excited vibrationally and ionized [24, 25]. UV-MALDI ionization is a laser desorption/ ionization assisted by a "matrix" that is a compound with an absorption band at the ionization laser frequency [26, 27]. When the mixed crystal is laser-irradiated, the matrix molecules absorb the laser photons and reach an electronic excited state. Both the matrix and sample molecules are heated rapidly, and sublime. The analyte ions have received high internal energy from the excited matrix molecules; at the point of ionization, their internal energy is generally high and broadly distributed.

In the positive-ion UV-MALDI TOF MS, the cationated oligosaccharide ions are stable enough to survive during the flight in the drift region. When the analytes are irradiated by strong laser power, some of them decompose spontaneously during the flight in the drift region (PSD). The cationated oligosaccharide ions such as [M + $\mathrm{Na}^{+}$found in positive-ion UV-MALDI and their PSD spectra show Y- and B-type fragment ions from glycosyl bond cleavage. These PSD spectra are very similar to the low-energy CID spectra of oligosaccharides in ESI-MS. So, it has been thought that UV-MALDI PSD and the lowenergy CID in ESI MS is the nearly same decomposition.

On the other hand, the deprotonated molecular ions of oligosaccharides in UV-MALDI MS acquired by negativeion mode decompose during the ionization process, and their fragment ions are detected in linear-mode UVMALDI TOFMS even though the laser irradiation strength is around threshold. This is because the deprotonated molecular ions of neutral oligosaccharides are unstable, and the UV-MALDI process can inject highly excited energy to the analyte molecules. So, in-source decay (ISD) occurs in negative-ion UV-MALDI TOF MS [13]. These ISD ions are mainly produced by cross-ring cleavage at the reducing terminal of the oligosaccharides. The phenomena do not occur in soft ionization of ES process without using unusual high capillary-skimmer voltages, which induce hard collisions in ES ionization process in low pressure region of the ES ion-source [28].

Since the PSD spectra of neutral oligosaccharides from chlorinated molecular ions are similar to the ISD spectra of negative-ion UV-MALDI TOFMS, the final PSD spectra we obtained are resulted in the very rapid decomposition from the "hot" or vibrationally exited deprotonated mo- 
lecular ion $[\mathrm{M}-\mathrm{H}]^{-}$, which is generated from the stable chlorinated molecular ion $[\mathrm{M}+\mathrm{Cl}]^{-}$during PSD time scale (see Scheme 1). From a consideration of the process, we can make the following hypothesis concerning PSD: the excitation of the matrix molecules by laser irradiation and the resulting broad distribution of high internal energy of the analyte molecule ions are responsible for the prompt decomposition of oligosaccharide molecules. Since, as we have already seen, the analyte molecules ionized by UV-MALDI have high internal energy at the time of ionization, the PSD from the chlorinated ions accompanying the deprotonation process follows a prompt reaction path. On the other hand, the ESI-CID in a hexapole or ion-trap cell is soft for collisional activation dissociation [29]. If the "hot" analyte molecular ions produced by UV-MALDI are cooled down, the high internal energy is reduced, and the analyte molecule ion can return to the ground state.

A hybrid method for combining a UV-MALDI ionsource with ion-trap/TOF MS has been developed [18, 30]. In this instrument, the ions from the UV-MALDI ion-source are trapped and undergo collisional cooling in the trap-cell. After that, the stable molecular ions are selected as precursor ions and can be activated by energy collisional activation. So, the energetic effects of UVMALDI on the "hot" and excited analyte molecular ions could be controlled or canceled in this UV-MALDI iontrap/TOF MS instrument. When the PSD spectra are compared with the product ion spectra of ion-trap/TOF MS from the chlorinated precursor ions, the spectral differences can be attributed to the characteristic features of UV-MALDI PSD.

\section{Conclusions}

The PSD spectra of neutral oligosaccharides of UVMALDI TOFMS acquired by negative-ion mode differ from the corresponding product ion spectra of ion-trap/ TOF MS. In our previous study, we found that the PSD spectra are almost the same as the ISD spectra in which

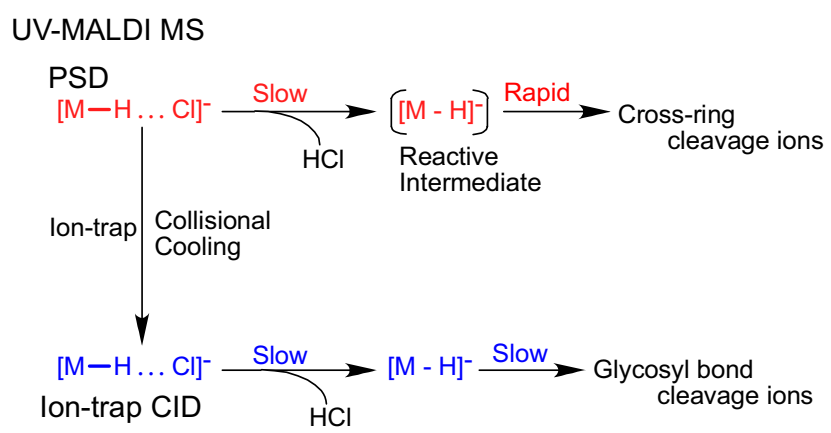

Scheme 1. Scheme of UV-MALDI PSD and UV-MALDI ion-trap CID. The red colored notation "Slow" indicates the slow reaction within the time window of PSD of tens or hundreds of microseconds. The blue colored notation "Slow" indicates the reaction during several tens of milliseconds. The red colored notation "Rapid" indicates the rapid reaction in the time window of ISD within nanoseconds. the cross-ring cleavage ions from the reducing terminal dominate in negative-ion mode UV-MALDI TOF MS measurements. The ISD ions are rapidly produced during laser irradiation within nanoseconds, and they are similar to the product ions from high-energy CID-MS/MS measurements, so the ISD in UV-MALDI MS proceeds via a prompt path $[13,20]$. The spectral similarity of PSD and ISD make it very likely that they have almost the same characteristics. Here, we assume two reaction steps in the PSD process; the first is deprotonation of the molecule from the chlorinated precursor ion $\left[\mathrm{M}+\mathrm{Cl}^{-}\right.$, and the second is the rapid decomposition of the unstable deprotonated molecular ion $[\mathrm{M}-\mathrm{H}]^{-}$(Scheme). Within the time window of PSD of the tens or hundreds of microseconds, the first reaction step progresses in the same timescale as the total PSD, and the following second step can progress as rapidly as the ISD process. It is the decomposition process of the deprotonated molecular ions [M $\mathrm{H}]^{-}$in PSD that is similar to that in the ISD process. In the PSD spectra from the chlorinated molecular ion [M + $\mathrm{Cl}^{-}$, all PSD ions are deprotonated ions in the PSD spectra, although the deprotonated molecular ions [M $\mathrm{H}]^{-}$themselves are not detected.

At the negative ionization, the negatively charged chlorine atom coordinates to the protons of the hydroxyl groups in neutral oligosaccharides. The coordinated proton is withdrawn by the chloride ion leading to deprotonation of the molecule as shown in the following; [M $\left.\mathrm{H}^{+} \ldots \mathrm{Cl}^{-}\right]^{-} \rightarrow[\mathrm{M}-\mathrm{H}]^{-}+[\mathrm{HCl}][15,31]$. It is certain that the deprotonated molecular ions are unstable and they are reactive intermediates in UV-MALDI of lactooligosaccharides. On the other hand, the chlorinated molecular ions can be stable even although they may have sufficient excess internal energy for the PSD process to occur. If the deprotonated molecular ions are produced from these chlorinated molecular ions having excited high internal energy, the deprotonated molecular ions cannot survive and they decompose rapidly in the PSD process, in a similar manner to the ISD process. So, the total PSD of neutral oligosaccharides appears to take place through a prompt reaction path resulting from the decomposition of deprotonated molecular ions $[\mathrm{M}-\mathrm{H}]^{-}$having excited high internal energy.

After the "hot" chlorinated precursor ions from UVMALDI are cooled by collisional cooling in the ion-trap cell, the high internal energy is reduced, resulting in precursor ions in the ground state, thought to be similar to that of the ES ionized molecular related ions. In the UV-MALDI ion-trap/TOF instrument, the deprotonated molecular ion $[\mathrm{M}-\mathrm{H}]^{-}$also loses its high internal energy and is in the ground state, and can survive during several tens of milliseconds [18, 28, 29]. Since C-type fragment ions are produced by the thermal dissociation after energy randomization during milliseconds order, it is reasonable that the C-type fragment ions dominate both in the product ion spectra of UV-MALDI ion-trap/TOF and ESI CID product ion spectra, and that these two methods exhibit similar spectral patterns except for small differences based on ionization methods. 


\section{Acknowledgments}

The authors thank Professor Hiroshi Nishihara and Dr. Masaki Murata of the University of Tokyo for their kindness in permitting them to use the UV-MALDI TOF mass spectrometer. They thank Dr. Masaki Yamada and Mr. Shin-ichiro Kawabata of Shimadzu Corporation, Kyoto, Japan, for their technical advice. They also thank Professor Takemichi Nakamura of RIKEN Institute, Professor Mitsuo Takayama of Yokohama City University, Dr. Kazuhiko Fukui of CBRC, AIST, and Professor Takae Takeuchi of Nara Woman's University for their helpful discussions. This work was done in part under the Glycoengineering Project supported by the New Energy and Industrial Technology Development Organization (NEDO) of Japan. It was also supported in part by a Grant-in-Aid for the 21st Century COE Program for Frontiers in Fundamental Chemistry from the Ministry of Education, Culture, Sports, Science, and Technology of Japan.

\section{References}

1. Dell, A.; Morris, H. R. Glycoprotein Structure Determination by Mass Spectrometry. Science 2001, 291, 2351-2356.

2. Zaia, J. Mass Spectrometry of Oligosaccharides. Mass Spectrom. Rev. 2004, 23, 161-227.

3. Stahl, B.; Steup, M.; Karas, M.; Hillenkamp, F. Analysis of Neutral Oligosaccharides by Matrix-Assisted Laser Desorption/Ionization Mass Spectrometry. Anal. Chem. 1991, 63, 1463-1466.

4. Spengler, B., Kirsch, D.; Kaufmann, R. Metastable Decay of Peptides and Proteins in Matrix-Assisted Laser Desorption/Ionization Mass Spectrometry. Rapid Commun. Mass Spectrom. 1991, 5, 198-202.

5. Domon, B.; Costello, C. E. A Systematic Nomenclature for Carbohydrate Fragmentations in FAB-MS Spectra of Glycoconjugates. Glycoconj. J. 1988, 5 , 397-409.

6. Yamagaki, T.; Nakanishi, H. Distinguishing of Linkage Isomers of Lactotetra Oligosaccharides by Using Relative Ion Intensity Analysis of Postsource Decay Fragment Ions in Curved-Field Reflectron MALDI-TOF MS. Anal. Sci. 2001, 17, 83-87.

7. Naven, T. J.; Harvey, D. J.; Brown, J.; Critchley, G. Fragmentation of Complex Carbohydrates Following Ionization by Matrix-Assisted Laser Desorption with an Instrument Fitted with Time-Lag Focusing. Rapid Commun. Mass Spectrom. 1997, 11, 1681-1686.

8. Harvey, D. J. Matrix-Assisted Laser Desorption/Ionization Mass Spectrometry of Carbohydrates. Mass Spectrom. Rev. 1999, 18, 349-450.

9. Yamagaki, T.; Nakanishi, H. Postsource Decay Fragmentation Analyses of Linkage Isomers of Lewis-Type Oligosaccharides in Curved-Field Reflectron Matrix-Assisted Laser Desorption/Ionization Mass Spectrometry: Combined In-Source Decay/Postsource Decay Experiments and Relative Ion Abundance Analysis. J. Mass Spectrom. 2000, 35, 1300-1307.

10. Harvey, D. J. Collision-Induced Fragmentation of Underivatized N-Linked Carbohydrates Ionized by Electrospray. J. Mass Spectrom. 2000, 35, 11781190.

11. Chai, W. G.; Piskarev, V.; Lawson, A. M. Negative-Ion Electrospray Mass Spectrometry of Neutral Underivatized Oligosaccharides. Anal. Chem. 2001, $73,651-657$
12. Pfenninger, A.; Karas, M.; Finke, B.; Stahl, B. Structure Analysis of Underivatized Neutral Human Milk Oligosaccharides in the Negative Ion Mode by Nano-Electrospray MS ${ }^{\text {; }}$ Part 1, Methodology. J. Am. Soc. Mass Spectrom. 2002, 13, 1331-1340.

13. Yamagaki, T.; Suzuki, H.; Tachibana, K. In-Source and Postsource Decay in Negative-Ion Matrix-Assisted Laser Desorption/Ionization Time-of-Flight Mass Spectrometry of Neutral Oligosaccharides. Anal. Chem. 2005, 77, 1701-1707.

14. Wong, A. W.; Cancilla, M. T.; Voss, L. R.; Lebrilla, C. B. Anion Dopant for Oligosaccharides in Matrix-Assisted Laser Desorption/Ionization Mass Spectrometry. Anal. Chem. 1999, 71, 205-211.

15. Cai, Y.; Jiang, Y.; Cole R. B. Anionic Adducts of Oligosaccharides by Matrix-Assisted Laser Desorption/Ionization Time-of-Flight Mass Spectrometry. Anal. Chem. 2003, 75, 1638-1644.

16. Nonami, H.; Tanaka, K.; Fukuyama, Y.; Erra-Balsells, R. B-Carboline Alkaloids as Matrices for UV-Matrix-Assisted Laser Desorption/Ionization Time-of-Flight Mass Spectrometry in Positive and Negative Ion Modes. Analysis of Proteins of High Molecular Mass and of Cyclic and Acyclic Oligosaccharides. Rapid Commun. Mass Spectrom. 1998, 12, 285-296.

17. Nonami, H.; Wu, F.; Thummel, R. P.; Fukuyama, Y.; Yamaoka, H.; Erra-Balsells, R. Evaluation of Pyridoindoles, Pyridylindoles, and Pyridylpyridoindoles as Matrices for Ultraviolet Matrix-Assisted Laser Desorption/Ionization Time-of-Flight Mass Spectrometry. Rapid Commun. Mass Spectrom. 2001, 15, 2354-2373.

18. Fountain, S. T.; Lee, H.; Lubman, D. M. Ion Fragmentation Activated by Matrix-Assisted Laser Desorption/Ionization in An Ion-Trap Reflectron Time-of-Flight Device. Rapid Commun. Mass Spectrom. 1994, 8, 407-416.

19. Vorm, O.; Roepstorff, P.; Mann, M. Improved Resolution and Very High Sensitivity in MALDI TOF of Matrix Surfaces Made by Fast Evaporation. Anal. Chem. 1994, 66, 3281-3287.

20. Garozzo, D.; Giuffrida, M.; Impallomeni, G.; Ballistreri, A.; Montaudo, G. Determination of Linkage Position and Identification of the Reducing End in Linear Oligosaccharides by Negative Ion Fast Atom Bombardment Mass Spectrometry. Anal. Chem. 1990, 62, 279-286.

21. Dell, A.; Morris, H. R. Fast-Atom Bombardment Mass Spectrometry for Carbohydrate Structure Determination. Carbohydr. Res. 1983, 115, 41-52.

22. Fukuda, M.; Dell, A.; Fukuda, M. N. Structure of Fetal Lactosaminoglycan: The Carbohydrate Moiety of Band-3 Isolated from Human Umbilical-Code Erythrocytes. J. Biol. Chem. 1984, 259, 4782-4791.

23. Mulroney, B.; Peel, J. B.; Traeger J. C. Theoretical Study of Deprotonated Glucopyranosyl Disaccharide Fragmentation. J. Mass Spectrom. 1999, 34, 856-871.

24. Cotter, R. J. Laser and Mass Spectrometry. Anal. Chem. 1984, 56, A485A504.

25. Cotter, R. J. Plasma Desorption Mass Spectrometry-Coming of Age. Anal. Chem. 1988, 60, A781-A793.

26. Karas, M.; Bachmann, D.; Hillenkamp, F. Influence of the Wavelength in High-Irradiance Ultraviolet Laser Desorption Mass Spectrometry of Organic Molecules. Anal. Chem. 1985, 57, 2935-2939.

27. Zenobi, R.; Knochenmuss, R. Ion Formation in MALDI Mass Spectrometry. Mass Spectrom. Rev. 1998, 17, 337-366.

28. Mulroney, B.; Traeger, J. C.; Stone, B. A. Determination of Both Linkage Position and Anomeric Conformation in Underivatized Glucopyranosyl Disaccharides by Electrospray Mass Spectrometry. J. Mass Spectrom. 1995, 30, 1277-1283.

29. McLuckey, S. A.; Goeringer, D. E. Slow Heating Methods in Tandem Mass Spectrometry. J. Mass Spectrom. 1997, 32, 461-474.

30. Michael, S. M.; Lubman, D. M. An Ion Trap Storage Time-of-Flight Mass Spectrometer. Rev. Sci. Instrum. 1992, 63, 4277-4284.

31. Cai, Y.; Cole, R. B. Stabilization of Anionic Adducts in Negative Ion Electrospray Mass Spectrometry. Anal. Chem. 2002, 74, 985-991. 